\title{
Article
}

\section{Branding in Pictures: Using Instagram as a Brand Management Tool in Professional Team Sport Organisations}

Anagnostopoulos, Christos, Parganas, Petros, Chadwick, Simon and Fenton, Alex

Available at http://clok.uclan.ac.uk/20958/

Anagnostopoulos, Christos ORCID: 0000-0001-7470-5191, Parganas, Petros, Chadwick, Simon and Fenton, Alex (2018) Branding in Pictures: Using Instagram as a Brand Management Tool in Professional Team Sport

Organisations. European Sport Management Quarterly . ISSN 1618-4742

It is advisable to refer to the publisher's version if you intend to cite from the work. http://dx.doi.org/10.1080/16184742.2017.1410202

For more information about UCLan's research in this area go to http://www.uclan.ac.uk/researchgroups/ and search for <name of research Group>.

For information about Research generally at UCLan please go to http://www.uclan.ac.uk/research/

All outputs in CLoK are protected by Intellectual Property Rights law, including Copyright law. Copyright, IPR and Moral Rights for the works on this site are retained by the individual authors and/or other copyright owners. Terms and conditions for use of this material are defined in the policies page.

\section{CLoK}

Central Lancashire online Knowledge www.clok.uclan.ac.uk

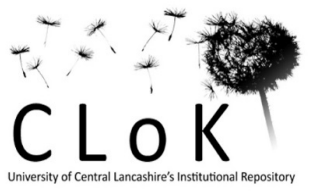


"As accepted for publication in European Sport Management Quarterly, (C)Taylor \& Francis"

http://dx.doi.org/10.1080/16184742.2017.1410202

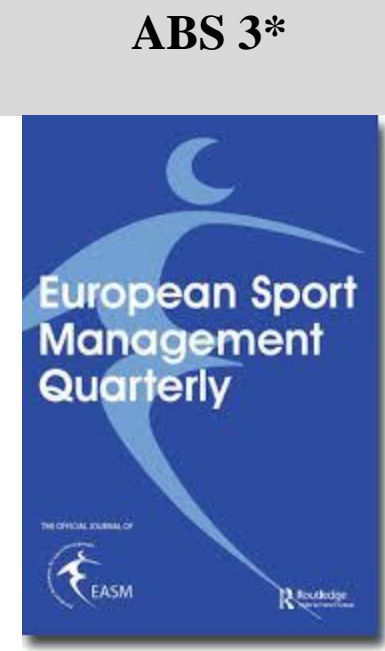

Christos Anagnostopoulos, (PhD), Molde University College (Norway) and University of Central Lancashire (Cyprus)

Petros Parganas, (DBA), University of Ioannina (Greece)

Simon Chadwick, (PhD), University of Salford (UK)

Alex Fenton (MSc), University of Salford (UK)

\title{
Branding in Pictures: Using Instagram as a Brand
}

\section{Management Tool in Professional Team Sport}

\author{
Organisations
}




\begin{abstract}
Research question/purpose -Instagram has become an increasingly popular tool for sport organisations to share visual content. This study aims to examine how professional team sport organisations use Instagram for branding purposes and to explore the given meaning of Instagram followers' reactions to the organisations' Instagram activity.

Research methods - The study was conducted in two phases. First, we analysed 2017 Instagram photos of two football teams from the English Premier League. Photos were categorised on product- and non-product-related brand attributes. Employing a quantitative content analysis technique, statistical analysis involved intra-case and inter-case relationships between brand attributes and Instagram's key fan engagement features (Comment and Like). Second, we analysed 2100 Instagram comments from a qualitative perspective in order to gain further insight into the fans' meanings associated with such posts.
\end{abstract}

Results and findings - The findings offer significant insights to sport marketers in their efforts to increase fan engagement through social media. For both of the examined football teams, product-related attributes were used significantly more often than non-product-related attributes and encouraged greater engagement from online followers. Against these brand attributes, fans' interaction through one of the Instagram's key engagement features is expressed through 'aspiring'-, 'belonging'-, 'criticising'- and 'loving'-based comments.

\title{
Implications -
}

The study shows that Instagram facilitates co-branding, while giving fans a more active role in the branding process through comments. We recommend a culture change whereby teams become more market-focused and communications-driven by employing a greater understanding of the semiotics of images and fan comments through the use of social media.

Keywords - Instagram, brand management, brand attributes, professional team sport organisations, social media 
Sport teams that operate in an increasingly professionalised environment must keep adopting advanced branding techniques in order to maintain their brand as both meaningful and distinctive from a consumer perspective and to differentiate it from competitors (Kaynak, Salman, \& Tatoglu, 2008). As such, professional sport teams have pioneered the widespread adoption of social media platforms (Filo, Lock, \& Karg, 2015; Pegoraro \& Jinnah, 2012), in an effort to nurture and maintain a two-way interactive communication with their fan bases (Clavio \& Walsh, 2013; Hambrick \& Kang, 2015; Hambrick, Simmons, Greenhalgh, \& Greenwell, 2010; Kassing \& Sanderson, 2010; Parganas \& Anagnostopoulos, 2015; Pegoraro, 2010; Pronschinske, Grozer, \& Walker, 2012; Stavros, Meng, Westberg, \& Farrelly, 2014; Williams \& Chinn, 2010). Most professional sport teams now maintain an online presence on several social media platforms and increasingly expand to new ones. However, less is known about the use of social media tools such as Instagram for building and communicating team brand associations. Some studies have examined the use of Facebook as a brand management tool in the context of US college athletics (Wallace, Wilson, \& Miloch, 2011), the challenges in developing a social media branding strategy (McCarthy, Rowley, Ashworth, \& Pioch, 2014), or the use of Twitter as a brand management tool (Parganas, Anagnostopoulos, \& Chadwick, 2015) in the context of professional football teams. Studies examining social media practices for sport organisations have predominantly focused on Facebook and Twitter (Abeza, O’Reilly, Seguin, \& Nzindukiyimana, 2015); while these platforms offer features for visual content interaction, they rely heavily on written content as the main communication medium for online users. Only recently have researchers started to explore the implications of tools that use visual content as their primary mode of communication. For instance, Hambrick and Kang (2015) explored Pinterest (a media content sharing tool) under the lens of a relationship marketing conceptual framework. Others have investigated how sport leagues can use YouTube for agenda-setting purposes (Zimmerman, 
Clavio, \& Lim, 2011). Recent studies have examined how Instagram can be used for engaging fans for sporting, business as well as social objectives (Kim \& Hull, 2017); as a self-presentation tool by Olympic athletes specifically (Geurin-Eagleman \& Burch, 2016), or by professional athletes more generally (Smith \& Sanderson, 2015). More in relation to the present study, yet outside the professional teams' context, Geurin-Eagleman and Burch (2017) found that sport brands that utilise user-generated content on their Instagram accounts elicit higher engagement from followers when posts have an overt focus on the product.

Further research is required, particularly from a professional sport team-branding perspective. In addition, the increased popularity of Instagram among sport teams, athletes and fans, combined with its potential marketing and branding implications as they mature (Geurin-Eagleman \& Burch, 2016), merits further exploration of this tool in the sport context. Several scholars have called for additional empirical research across different social media platforms (cf., Frederick, Lim, Clavio, Pedersen, \& Burch, 2014; Lebel \& Danylchuk, 2014; Pedersen, 2014; Pronschinske et al., 2012; Rowe, 2014), particularly for marketing purposes and through longitudinal studies (Abeza et al., 2015), and crucially, investigations of social media consumer behaviour (Ratchford, 2015).

The present study answers these calls. Drawing theoretical insights from widely adopted sport team branding models (e.g., Bauer et al., 2008; Gladden \& Funk, 2002; Ross, James, \& Vargas, 2006), we aim to analyse how two professional sport teams have used Instagram to communicate their brand image and its impact on the responses of their online following.

\section{Literature review}

\section{Sport branding}

The sport industry is nowadays seen as part of the wider entertainment industry (Bauer et al., 2008). While on-field success remains important, professional sport teams need to adapt to 
the ever-expanding entertainment industry by leveraging their brand equity (Rein, Shields, \& Grossman, 2015). Brand equity exists when consumers are familiar with the brand and perceive some positive associations (such as thoughts and ideas) towards that brand (Aaker, 1991; Keller, 1993). Accordingly, the brand equity of sport teams is derived from the brand associations sport consumers attach to them (Gladden \& Milne, 1999).

Over the last decade, researchers have developed and refined techniques and scales that illustrate the various associations consumers link to their preferred sport teams (Bauer et al., 2008; Gladden \& Funk, 2002; Ross et al., 2006; Ross, Russell, \& Bang, 2008), leagues (Kunkel, Funk, \& King, 2012) and athletes (Arai, Ko, \& Ross, 2014). The present study focuses on sport teams brand associations, which represent the attributes, benefits and attitudes a consumer perceives as being linked to a given team (Gladden \& Funk, 2002). Gladden and Funk (2002) were the first to identify the brand associations fans might have for their favourite sport team. Based on Keller's (1993) hierarchy of brand associations (attributes, benefits, and attitudes), they proposed the Team Association Model (TAM) and contended that there were 16 different association dimensions, divided into product-related attributes (including success, star player, head coach, team's management), non-productrelated attributes (including logo, stadium, tradition, product delivery), symbolic benefits (including fan identification, peer group acceptance), experiential benefits (including escape, nostalgia, pride in place), and attitudes (such as importance, knowledge, affective reaction). They further applied and empirically tested their model in the United States sport context. Bauer et al. (2008) provided a modified version of the TAM, including product-related attributes (success, star player, head coach, team performance), non-product-related attributes (management, logo, stadium, history and tradition, club culture and values, fans, sponsor, regional provenance), benefits (pride, fan identification, nostalgia, escape, socializing, 
emotions, entertainment, peer group acceptance), and attitudes (or affect). They further tested their model in the context of German professional football.

Building predominantly on the models of Gladden and Funk (2002) and Bauer et al. (2008), Parganas et al. (2015) developed a sport team branding model and applied it to a professional football club in the context of Twitter. Parganas et al. argued that sport branding models based on Keller's (1993) structure offer some advantages from a corporate standpoint, as such models offer dimensions that the sport marketer can at least partly control. Therefore, their model constituted of just two broader categories: product-related attributes that is, those features that contribute directly to the product (the actual game); and nonproduct-related attributes, which are features relevant to the consumption of the product and influence the perceptions of fans towards the team's brand (Table 1). Parganas et al. (2015) showed that brand associations communication can be transferred in the social media context, with varying degrees of fan interaction, as fans respond more often to product-related attributes than to non-product-related ones. However, given (a) the nature of Twitter to offer more frequent and disposable updates (Price, Farrington, \& Hall, 2013) which could lead to different patterns of fan responses, (b) the single case study approach adopted and, (c) the limited time-frame during which the study was carried out, additional research is expected to advance our understanding of the use of social media as brand management tools in the professional sport teams context. Therefore, while the present study adopted Parganas et al.'s (2015) analytical model, it also addresses methodological shortcomings identified therein by offering empirical insights from an inter-case perspective over a longer period of time (that is, a full playing season). Against this background, the following research question (RQ) is put forward:

RQ1: What product- and non-product-related attributes are professional sport teams communicating through Instagram? 


\section{INSERT TABLE 1 ABOUT HERE}

\section{Social media branding}

Social media have been defined as "the tools, platforms, and applications that enable consumers to connect, communicate, and collaborate with others" (Williams \& Chinn, 2010, p. 422). Social media encompass a wide range of online, word-of-mouth forums including blogs and microblogs, company-sponsored discussion boards, and social networking websites (Kaplan \& Haenlein, 2010), and new tools are constantly being added. The number of social media users globally reached almost 2.51 billion during 2017, and is predicted to grow to 2.95 billion by 2020 (Statista, 2017). Individuals can use the platforms for information sharing and socialisation purposes, while companies can benefit by increasing brand awareness and by promoting their brands (Hambrick et al., 2010; Kassing \& Sanderson, 2010; Pegoraro, 2010). This magnitude of everyday interactions generates large amounts of brand-related information, which influence the opinions of all online users (Smith, 2009).

For organisations, social media provide a direct communication link to consumers, which enables them to communicate a specific brand image (Wallace et al., 2011) and shape brand associations (Yan, 2011). Therefore, social media can play a crucial role in building appropriate perceptions and attitudes in a consumer's mind, which is necessary for building a strong brand (Keller, 2009; Schivinksi \& Dabrowski, 2015). Indeed, organisations from various economic sectors have integrated social media into their business models as part of their communication and branding strategies (Anagnostopoulos et al., 2016; Bruhn, Schoenmueller, \& Schaefer, 2012; Hautz, Dennhardt, \& Fuller, 2013; Kim \& Ko, 2012; Parganas et al., 2015; Schivinski \& Dabrowski, 2015; Shen \& Bissell, 2013).

Today's consumers become increasingly active in online environments, seeking to engage in increasing levels of collaboration and interactivity with organisations (Kietzmann, Hermkens, McCarthy, \& Silvestre, 2011). Customer engagement, which is a customer's level 
of cognitive, emotional, and behavioural investment in specific brand interactions (Hollebeek, 2011), explicitly accounts for consumers' interactive brand-related dynamics (Brodie, Hollebeek, Juric, \& Ilic, 2011). The theoretical notion of "interactive experience" that underlies the engagement concept is also at the heart of social media. Social media users may engage in interactive behaviours (using features offered by online tools) in brand communities, such as commenting on the brand, expressing support or criticism and sharing information with social connections (Gummerus, Liljander, Weman, \& Pihlstrom, 2012).

Indeed, sport teams have been early adopters of social media tools, not only to maintain and to nurture two-way communication with their fans (Hambrick \& Kang, 2015; Hambrick et al., 2010; Parganas \& Anagnostopoulos, 2015), but also to obtain information about those consumers' preferences and habits (Browning \& Sanderson, 2012), to increase brand awareness (Eagleman, 2013) and to promote and attract sponsors (Eagleman \& Krohn, 2012; Parganas \& Anagnostopoulos, 2015). Furthermore, the increasing popularity of these platforms represents an opportunity for sport teams to communicate with their current fan base and to expand it (Clavio \& Walsh, 2013). On the other side, sport consumers, because of their personal interest in and engagement with the sport product, are increasingly searching for relevant content from online sources (Broughton, 2012; Whiteside, Yu, \& Hardin, 2012) and have come to expect their favourite team to communicate and engage with them directly through social media platforms (Ballouli, 2010). Because of the inherent characteristics of social media, geographical barriers do not apply to fans, which allows them to follow the activities of their favourite team regardless of their location (Gibbons \& Dixon, 2010).

Within the social media context, Instagram is a tool that utilises photographs as its primary communication mechanism (Graham, 2013) and is gaining significant popularity among athletes and sport organisations worldwide (Clavio, 2013). Since its launch in October 2010, Instagram has attracted more than 700 million active users, making this medium more 
than twice the size of Twitter (Constine, 2017) and the best platform for brands (Koetsier, 2013). ). As of the second quarter of 2017, more than 95 billion photos have been uploaded and shared, resulting in more than 4.2 billion daily interactions (Instagram, 2017). Similar to other social media tools, users register for free and are then instantaneously able to share photos or follow other registered users and view their shared photos. Recently expanded capabilities include sharing videos, and sharing photos with specified users through direct messaging (Baig, 2013; Miners, 2013). In addition, several industry insiders have emphasised Instagram's wide adoption among global brands for brand awareness and brand management purposes (Simply Measured, 2013; Shively, 2014), reporting 32 per cent increases in ad recall rates and 10 per cent increases in brand message recall (Truong, 2014).

Instagram's popularity, along with its ability to share media content, makes it a particularly effective tool for sport teams. All of the teams in the 2015-2016 EPL season have established an official Instagram presence, and research indicates that visual content (such as pictures and videos) boosts fan engagement (Clavio, 2013; Hambrick et al., 2010). Sport teams can share specific facets of the team's image in order to increase the involvement of fans (Ferrand \& Pages, 1999). Furthermore, as part of the wider social media family, Instagram can positively impact the affiliation of fans towards their team (Popp \& Woratschek, 2016) as well as the team's revenues (Broughton, 2012). Teams can use Instagram to reach their current and new audiences, encourage interactions with the sport product, and build positive associations towards their brand.

With this in mind, the present study aims to address two more interconnected questions:

RQ2: To what extent do Instagram's key engagement metrics of Comment and Like correspond to brand attributes? 
RQ3: How do Instagram followers of sport teams respond and react to brand attributes?

In addressing the abovementioned questions, this study makes three main contributions. First, it increases our understanding of the use of social media as brand management tools; second, it provides insights into the effectiveness and meaning of certain brand attributes in terms of fan interaction and engagement; and third, it offers managerial implications of successful social media practices in sport team branding.

\section{Method}

The study was exploratory in nature and used quantitative and qualitative content analyses to address its research purpose. Content analysis is a systematic and replicable method for analysing written and/or visual content (Riffe, Lacy, \& Fico, 2005) and has been shown to be an appropriate method to examine social media in sport settings (Gibbs, O’Reilly, \& Brunette, 2014; Hambrick \& Kang, 2015; Kassing \& Sanderson, 2010; Ozsoy, 2011; Parganas et al., 2015; Pegoraro, 2010).

\section{Sample selection}

The study examined how two EPL teams, namely Liverpool FC (LFC) and Manchester United (MU), use Instagram to manage their brand images. The EPL was selected because of its global fan following (1.46 billion - or 70 per cent of the world's estimated 2.08 billion football fans) (EPL, 2015) as a result of the explosive international popularity of football (Blumrodt, Bryson, \& Flanagan, 2012). Furthermore, a successful and strong league brand such as the EPL is expected to have a reciprocal impact on sport team members (Kunkel et al., 2012). The two selected teams belong to the elite European football clubs in terms of revenues (Deloitte, 2017), brand value (Brand Finance, 2015), size of fan base (Sport+Markt, 2010), and social media followers (Socialbakers, 2017). Both teams are positioned at the top places among EPL clubs in terms of Instagram followers. As of May 
2017, MU is placed first with 17.6 million followers, while LFC had a much lower, but still respectable, figure of 4.1 million followers. MU and LFC are historically the two most successful English football teams, with the most and second-most domestic league titles, respectively. Considering the high brand value of both teams, their athletic success, as well as their worldwide fan base, they are regarded as representative exemplars of elite professional team sport organisations. In order to answer the study's research questions, it was necessary to select two teams with a substantial following and sufficient comments. Our familiarity with both teams, from a semiotic and historical perspective, helped make meaning of the images and fan comments and opened up potential for access and future research studies. Although our sample is delimited to the aforementioned two sport teams, it is important to note that the unit of analysis here is 'Instagram content' and not the organisations this content derives from.

\section{Quantitative Data collection}

One of the authors followed the official Instagram accounts of LFC (www.instagram.com/liverpoolfc) and MU (www.instagram.com/manchesterunited) from 1 August 2015 to 25 May 2016 (a total of 10 months, or 299 days, covering the entire 2015/2016 playing season) and collected the shared photos. During this period, LFC and MU played 63 and 59 matches, respectively, in all domestic and European competitions, including four matches against each other in the EPL and European leagues. It has been a cautious decision to collect data during the on-season only as this is essentially when teams are fulfilling their core purpose: playing matches. Furthermore, teams' brand assets (most notably their star players) are generally available during this period and therefore readily provide the content for social media communications. We decided against analysing data gathered outside the regular playing season for three main reasons. First, during the offseason, players and managers (both on-field and off-field) are often away from a team on 
holidays or on international duties. Second, because matches are often not played for significant periods during these months, the nature of any content that can be generated is significantly different to that generated during the on-season. Third, teams' playing rosters during the off-season are not finalised, which means that a lot of fan engagement with communications is based around rumour, conjecture and speculation about new player signings. Whilst accepting the value of analysing data gathered during the off-season, we felt that analysing data gathered during both the on-season and the off-season would generate large, potentially unmanageable amounts of data. Therefore, we propose an analysis of offseason data as a future research opportunity, both as a stand-alone study and as the basis for a tightly defined comparative analysis involving posts during the on-season.

In the social media space, engagement often refers to a consumer "taking some action beyond viewing or reading" (Paine, 2011, p. 60). Depending on the social media tool, this may include "liking" a brand's post, adding a comment to a brand's post, or sharing a brand's post with other users. Therefore, the assessment of engagement in this study (for Phase 1) was measured as a result of the two key types of activities offered by Instagram, namely Comment and Like, an approach also adopted elsewhere (e.g., Geurin-Eagleman \& Burch, 2016). Instagram users can click on the Like button to show their approval or agreement with a post without verbal expression, while a comment on a post is the expression of a textual opinion. Thus, a Comment is seen as a higher level of engagement because it requires more effort by the users to directly respond to organisational messages, while offering them the opportunity to participate in ongoing dialogues with other commenting users (hence preferred for Phase 2). During the period of study, the data collection process included the quantitative collection of the responses (frequency of occurrence) of each post in terms of Comment and Like. In addition, each post was revisited one month after its first appearance to account for any changes in the frequency of the responses. 


\section{Quantitative Codebook}

Each photo was categorised based on the brand attributes of the adopted branding model (Table 1) by analysing its specific emphasis. Such an approach is consistent with similar studies in the existing literature (e.g., Parganas et al., 2015; Wallace et al., 2011), while Instagram's feature of providing a supportive description for each uploaded photo served this purpose well. In order to facilitate the comparison between product and nonproduct related attributes, photos qualified for only one brand attribute type (for example, either product-related or non-product-related). In instances where photos could not be clearly assigned to any single brand attribute type, the post was assigned to the category Other. Such posts included a photo showing the head coach analysing the next opponent. In this case, the post could be regarded as either product-related (Head Coach, emphasis placed on who is talking) or non-product-related (Event's Image, emphasis placed on what is being discussed). Within the brand attribute category, photos could be assigned to more than one brand attribute. For example, a picture of fans (non-product-related brand attribute Fans) in front of one team's home stadium (non-product-related brand attribute Stadium) or a picture showing several players (product-related brand attribute Star Player $(s)$ ) celebrating a teams' goal (product-related brand attribute Team Success).

\section{Quantitative Coders and reliability}

The first two authors participated in the coding of all photos. Inter-coder reliability was measured using two methods for all posts: (a) the percentage of agreement between the raters, and (b) Cohen's kappa. The latter is a statistic that measures inter-coder agreement for categorical items and takes into account the level of agreement that occurs by chance. The percentage of agreement was 95.6 per cent and Cohen's kappa was 0.94, both of which are above the thresholds of 80 per cent and 0.7, respectively (Frey, Botan, \& Kreps, 2000), 
indicating a high degree of reliability. Discrepancies between the two coders were resolved through discussion.

\section{Qualitative data collection and analysis}

Although fans' engagement against product- and non-product-related brand attributes can be portrayed through the quantitative phase, this method would not have enabled us to capture the meaning fans attach to such engagement. In an attempt to do so, the analysis in the qualitative phase followed both inductive and deductive reasoning. We initially undertook an analysis of a random sample of comments $(n=100)$ attached to just six photographs posted by each team $(n=12)$. For this sample, the last two authors employed an inductive descriptive coding process (Miles et al., 2013) in which Instagram followers' comments were used to develop codes. First, the comments from the sample were entered in an Excel spreadsheet and each comment was verified for accuracy by comparing the text to the actual post. Second, each comment was examined for units of meaning and was labelled with a single descriptive code (Miles et al., 2013). Third, the coders of this phase met to compare and reconcile the codes they had derived, which led to codes being confirmed, merged or rejected. During steps 2 and 3 in the outlined process, a master list of codes was recorded containing the code and a definition of what that code meant, which resulted in an accurate and consistent coding process from one message to the next (Miles et al., 2013). Always following Miles et al.'s (2013) analytical procedures, the fourth stage entailed the 'pattern coding method', which pulls together much material from the previous stages into more meaningful and concise units of analysis (Miles et al., 2013). The goal of the fifth and last stage of this inductive coding process was to focus on identifying patterns and key excerpts from the sampled comments attached to Instagram posts that might serve as representative themes describing the essence of what the followers collectively communicated through their comments (Miles et al., 2013). 
Following the inductive process that resulted in four higher-order main themes (see Table 6 further), we analysed a random sample of Instagram photos posted by the official MU ( $n=50)$ and LFC ( $n=50)$ accounts, resulting in an examination of 2100 comments by followers in response to these posts. The NVivo software program facilitated the axial coding (Strauss \& Corbin 1998), where a deductive approach was used to quantify, group, and synthesise the data around the four themes as the means of analysing the comments. Intercoder reliability was measured for this stage too, using Cohen's kappa (0.82), a score indicating an acceptable degree of reliability.

\section{Findings}

\section{Quantitative Results}

The quantitative sample consisted of a total of 2107 Instagram posts comprising 2,963,928 Comments and 255,676,342 Likes (Table 2). All posts from the two teams resulted in both forms of engagement by their fans; that is, every post by both teams garnered a significant amount of Likes and Comments.

\section{INSERT TABLE 2 ABOUT HERE}

\section{Brand attributes}

Intra-case results, LFC. LFC placed its strongest emphasis on the attributes of Star Player(s) and Team Success (34.77 per cent and 23.69 per cent, respectively), followed by Head Coach (12.46 per cent), Event's Image (8.63 per cent) and Club's History and Tradition (5.13 per cent). Overall, LFC placed more emphasis on product-related posts ( 751 posts, 70.92 per cent) than non-product-related posts (302 posts, 28.51 per cent). Six posts ( 0.57 per cent) could not be clearly assigned to any of the above categories and were therefore labelled as Other. The two-by-one chi-square analysis revealed that LFC's product-related content was indeed significantly higher than non-product-related content: $\chi^{2}(1, N=1053)=191.45, p<.001$. 
Intra-case results, MU. MU's Instagram posts emphasized the attributes of Star Player(s) (33.09 per cent) and Team Success (21.42 per cent), followed by Club's History and Tradition (10.52 per cent) and Event's Image (8.85 per cent). Overall, MU placed more emphasis on product-related posts (588 posts, 56.07 per cent) than non-product-related posts (446 posts, 42.50 per cent). A total of 15 posts (1.43 per cent) could not be clearly assigned to any of the latter categories and were therefore labelled as Other. Further statistical analysis revealed that product-related content was significantly higher than non-product-related content: $\chi^{2}(1, N=1034)=19.501, p<.001$.

Inter-case results, $L F C$ and $M U$. Both teams were almost equally active during the playing season (LFC: 1059 posts, MU: 1048 posts). The two-by-one chi-square analysis confirmed this observation, as no significant difference between the number of posts of the teams was revealed: $\chi^{2}(1, N=2107)=0.057, p=.81$. However, LFC posts significantly more productrelated posts than MU: $\left.\chi^{2}(1, N=1339)=19.842, p<.001\right)$. On the other hand, MU posts significantly more non-product-related posts than LFC: $\chi^{2}(1, N=748)=27.722, p<.001$. Looking at each brand attribute separately, significant differences between the two teams were observed in terms of the attributes of Head Coach, Management, Club's History and Tradition, Club's Culture and Values, Fans, and Stadium. Table 3 displays the breakdown of brand attributes by team and indicates any statistically significant differences between the two teams.

Furthermore, both teams dedicated approximately one-third of their posts to the brand attribute Star Player(s), which is clearly the most popular brand attribute. Looking at this brand attribute in more detail, it becomes evident that posts picturing star players are divided into the following categories: (a) match, including action during the match, listening to the coach, and celebrating a goal; and (b) non-match, including performing training drills, listening to the coach, having fun in training, travelling to the match, and signing contracts. 
For both clubs, posts picturing star players' actions during the match were more popular than posts picturing non-match activities (LFC: 76.90 per cent and MU: 66.85 per cent), while posts picturing a star player celebrating a goal during a match were the single most popular of all categories (LFC: 45.38 per cent and MU: 44.66 per cent).

\section{INSERT TABLE 3 ABOUT HERE}

\section{Fan engagement}

Fan engagement was measured using the number of Comment and Like of each photo (brand attribute). Table 4 shows the overall mean number $(M)$ of comments and likes per brand attribute for both teams.

A bivariate correlation revealed that the number of comments and number of likes a photo received had significant positive correlation with each other: $r(1059)=0.63, p<.01$ and $r(1048)=0.59, p<.01$ for LFC and MU, respectively. This indicates that, for both teams, as the number of comments on a photo increased, so too did the number of likes on that photo.

\section{INSERT TABLE 4 ABOUT HERE}

Intra-case results, $L F C$. LFC fans commented significantly more on product-related attributes than on non-product-related attributes: $\chi^{2}(1, N=952080)=481904.54, p<.001$. ANOVA results revealed a significant effect of the photo content (that is, the brand attribute) on the number of comments at the .01 level $[F(10,1053)=5.245, p<.001]$. Post hoc comparisons using the Scheffe test indicated that the mean number of comments of the brand attribute Head Coach was significantly higher than all other brand attributes at the .05 level of significance.

LFC fans liked product-related posts significantly more than non-product-related posts: $\chi^{2}(1, N=78436461)=481904.54, p<.001$. ANOVA results revealed a significant effect of the photo content on the number of likes at the .01 level $[F(10,1053)=98.326, p<.001]$. Post hoc comparisons using the Scheffe test showed that likes of the brand attributes Head 
Coach and Star Player(s) were significantly higher than likes of all other brand attributes at the .05 level of significance.

With particular regard to the most popular brand attribute, namely Star Player(s), ANOVA results revealed significant differences for the number of likes on the types of photos of players. The star player category had a significant effect on the number of likes at the .01 level $[\mathrm{F}(7,368)=5.45, \mathrm{p}<0.001]$. Post hoc results revealed that likes of pictures of players celebrating goals were significantly higher than likes of all other star player categories at the .05 level.

Additionally, ANOVA results revealed significant differences for the number of comments on the types of photos of players at the .01 level $[F(7,368)=3.41, p<0.001]$. Post hoc results revealed that comments on pictures presenting the player celebrating a goal during the match were significant higher than comments on all other star player categories at the .05 level.

Intra-case results, $M U$. MU fans comment significantly more on product-related than on nonproduct-related attributes: $\chi^{2}(1, N=1996391)=478643.43, p<.001$. ANOVA results revealed that the photo content significantly affects the number of comments $(F(10,1030)=121.235$, $p<.001)$ at the .01 level. Post hoc comparisons using the Scheffe test indicated that the mean number of comments of the brand attribute Team Success was significantly higher than all other brand attributes at the .05 level.

Similarly, MU fans liked product-related posts significantly more than non-productrelated posts: $\chi^{2}(1, N=174682448)=599875.14, p<.001$. ANOVA results revealed that the photo content significantly affects the number of likes $\left(F(10,1030)=531.242, p^{<.001}\right)$. Furthermore, post hoc comparisons revealed that the attributes Star Player(s) and Club's History and Tradition received significantly more likes than the other brand attributes. 
With particular regard to the brand attribute Star Player(s), ANOVA results revealed significant differences for the number of likes and comments on the categories of photos of players. There was a significant effect of star player photo category on the number of likes at the .01 level $[\mathrm{F}(7,347)=4.47, \mathrm{p}<0.001]$. Post hoc results revealed that likes of pictures presenting the player celebrating a goal during the match were significantly higher than likes of all other star player categories at the .05 level.

Similarly, the star player photo category had a significant effect on the number of comments at the .01 level $[\mathrm{F}(7,347)=3.49, \mathrm{p}<0.001]$, while comments on pictures presenting the player celebrating a goal during the match were significantly higher than comments of all other star player categories at the .05 level.

Inter-case results, $L F C$ and $M U$. In order to investigate differences between the fans' responses of the two teams, the ratio of Instagram followers to comments (likes) was used. This normalisation of numbers ensures that the most accurate results possible are reported. LFC fans are more active and engaged on Instagram than their MU counterparts (Table 5). In terms of Comment, there is a significant difference on product-related $\left(\chi^{2}(1\right.$, $N=2284027)=81560, p<.001)$ and non-product-related attributes $\left(\chi^{2}(1, N=664444)=24567\right.$, $p<.001)$. Similarly, in terms of Like, there is a significant difference on both product-related $\left(\chi^{2}(1, N=153549379)=1346782, p<.001\right)$ and non-product-related attributes $\left(\chi^{2}(1\right.$, $N=99569530)=42476, p<.001)$.

\section{INSERT TABLE 5 ABOUT HERE}

\section{Qualitative Results}

We complemented the above findings of how professional sport teams utilise their social media platforms (Instagram, for that matter) against product- and non-product brand attributes by analysing the comments attached to Instagram's posts in order to capture the fans' meanings associated with such posts. Our findings indicate that fans' comments fall 
under four broad categories: aspiring, belonging, criticising and loving. 'Aspiring' refers to positive comments that aspire for the team to succeed and is largely associated with the product-related brand attribute 'team success'. 'Belonging' refers to positive comments that demonstrate unity or a particular bonding with the team and is linked to engagement associated with both product and non-product brand attributes. 'Criticising' comments have negative connotations and are predominantly critical of the three product-related brand attributes. 'Loving'-based comments feature the word love or a heart/love emoticon directed as a positive thing toward the team (including product and non-product attributes). Illustrative data examples of these categories are provided in Table 6.

\section{INSERT TABLE 6 ABOUT HERE}

\section{Discussion}

As fans gravitate toward different social media outlets, sport organisations can establish online presences to further their brand-building processes. This study is the first to examine how professional sport teams use Instagram to manage their brand image and interact with their worldwide audiences. The process was facilitated by examining how two renowned British football teams perform in terms of communicated brand attributes and key fan engagement features of Instagram.

\section{Theoretical contributions}

With regard to the first research question (RQ1), the findings showed that both clubs use a variety of both product-related and non-product-related attributes in their Instagram posts, albeit with significantly greater importance on product-related attributes. Posts emphasizing Star Player(s), Team Success and Head Coach covered about 70 per cent of LFC's total posts of LFC and 56 per cent of MU's. Such results are similar to those of Parganas et al. (2015), which indicated significantly broader coverage of product-related tweets. This suggests 
similarities in branding activities across different social media channels, which might emanate from a strategic viewpoint of the sport teams. A significant difference has been observed on posts regarding the product-related brand attribute Head Coach. LFC's midseason appointment of the German star-coach Juergen Klopp as the club's new head coach resulted in a large number of posts from the team, not only at the time of signing but also to a large extent afterwards. Based on these findings, it is plausible that the instant messaging features of social media allow frequent coverage of product-related attributes (match updates and the like), and teams can bypass traditional media in terms of information sharing and timely updates of team-related stories (O’Shea \& Alonso, 2011). In addition, taking into account that product-related attributes are associated with higher purchase intentions (Kaynak et al., 2008), the eventual strategies of both teams might aim to influence the consumption behaviour of their fans.

Non-product-related attributes also received a fair share of attention from the teams. Significant statistical differences between the two teams were observed with regard to the attributes of Club's History and Tradition, Club's Culture and Values, Fans, and Stadium. In all cases, MU places significantly more emphasis on these attributes than LFC. Most Instagram posts of both teams related to their history and tradition (Club's History and Tradition), the upcoming match (Event's Image), the home stadium (Stadium) and/or addressed fans (Fans) directly. Unlike product-related attributes, the importance of nonproduct-related attributes is based on their relative consistency over time. That is, contextual factors such as the team's history or the home stadium can strengthen the team's brand (Boyle \& Magnusson, 2007) and are foundations upon which team-fan relationships can be built and can help to overcome emotional ups and downs caused by wins, losses, changes of players, and replacements of coaches (Bauer et al., 2008). 
Another common characteristic was the small proportion of Instagram posts (1.29 per cent for LFC and 2.86 per cent for MU) reflecting community service activities such as promoting social initiatives or visits to children's hospitals. This kind of post provides fans with a different perspective as they learn more about their team and its players off the playing field and, in addition to purely team-related information, offers another way to enhance fans' connections to the club (Pronschinske et al., 2012; Wallace et al., 2011). The small numbers of such posts are consistent with previous studies (Parganas et al., 2015) and could be explained by the establishment of independent, non-profit charitable foundations by all teams in the EPL (Anagnostopoulos, Byers, \& Shilbury, 2014) that now use their own social media accounts to interact with various stakeholders (Anagnostopoulos et al., 2016).

Common to both teams, the least communicated non-product related attributes were the clubs' Sponsor and Management. While the scarce content about the teams' owners might be explained given the expected low interest from and appeal to fans, the very limited amount of content regarding sponsorship and merchandise issues in general contradicts previous studies, particularly in the North American sport context (Hambrick \& Kang, 2015). Such differences can be attributed to the way North American sport teams operate compared to European teams. Historically, the relationships European teams have with their local communities and traditions are of major importance and have implications for their very operation (Anagnostopoulos \& Shilbury, 2013). In contrast, North American teams have been founded on purely business principles and mainly operate as franchises (Beech \& Chadwick, 2007). Such differences predicate different marketing communication approaches. For instance, in the European context, promotional posts can discourage or even irritate fans (McCarty et al., 2014), who tend to see themselves as "co-owners" of the team and social media communities as "their" space (Boyd \& Ellison, 2008). 
With regard to second research question (RQ2), the positive correlation between the number of comments and the number of likes a photo received shows that the latter can trigger interactions towards the same direction, despite differences in the interactions as such. That is, while comments represent a stronger form of engagement (Cho, Schweickart, \& Haase, 2014), likes are equally important as they multiply the reach of the post (Lipsman, Mudd, Rich, \& Bruich, 2012), thereby increasing brand awareness. Responses (in terms of Comment and Like) to product-related content were significantly higher than responses to non-product-related content for both teams. Inter-case statistical analysis revealed that the number of LFC fan responses to both product and non-product-related attributes were significantly higher than the number of responses by MU fans. Although such a result may be treated with some caution, LFC's strategy to focus more heavily on product-related attributes seems to have created a larger impact in terms of fan engagement. For instance, Juergen Klopp created a large amount of online conversation; during the week preceding his appointment, the term "Klopp" was the top social media subject in more than 132 countries worldwide (Embury-Dennis, 2015). This provides further evidence about the ability of social media not only to nurture brand-related conversations and to create brand awareness (Cooper, 2010; Hanna, Rohm, \& Crittenden, 2011; Yan, 2011; Clavio \& Walsh, 2013; Hambrick \& Kang, 2015; Pronschinske et al., 2012; Williams \& Chinn, 2010), but also to communicate key events such as the signings of new players and/or coaches that trigger pronouncements of new hope (that is, 'aspiring') amongst fans (Stavros et al., 2014). In the case of MU, the most commented Instagram posts were photos showing the final scores (and scorers) of games against other EPL teams and exclusive team photos from training sessions. These findings aligned closely with those of other researchers (Clavio, 2013; Hambrick et al., 2010; Pegoraro, 2010) and industry experts (McLaren, 2013), who contended that audiences value "behind the scenes" information and content about their team and players. 
In total, fans of both clubs provided almost 3 million comments and 250 million likes for the period of quantitative study. Thus, it is evident that the emergence of social media has empowered consumers to become actively involved in generating brand-related content through four main types of comments: aspiring, belonging, criticising and loving. Our attempt to capture the fans' meanings of such engagement (RQ3) brought characteristics of postings that fall outside existing conceptualisations and variables associated with fans, brands and professional sport teams. For example, whilst there is a body of work focusing on the concepts of identification and attachment (e.g. Greenwood, Kanters, \& Casper, 2006; Robinson \& Trail, 2005), the sport marketing and branding literatures have so far provided scant consideration of 'belonging'. In the present study, 'belonging' appears as the apparent need for fans using social media to be part of a group, conversation or occurrence, linked to their favoured team or brand. This observation does link to references in the sport branding regarding; for example, club values, and social media seem to fulfil a post-engagement function by enabling fans to interact and communicate with one another at times other than a match-day.

Furthermore, notwithstanding the literatures on fan affiliation and identification with sport teams, the sport marketing literature contains no significant references to brand 'loving'. This is similarly characteristic of the wider marketing literature, although Batra, Ahuvia and Bagozzi (2012) and Albert and Meruka (2013) have introduced and explored the notion that consumers fall in love with brands. 'Loving' is inevitably linked to the breadth, depth and longevity of relationships and links to elements such as partners sharing values. As such, it seems understandable that sport fans might be thought to have a 'loving' relationship with a team. However, social media has introduced new dimensions to the notion of 'loving', which, in the light of our findings, we believe is two-fold. First, social media easily enables individuals to readily and openly make public statements of 'loving'; second, the ease with 
which 'emojis' (particularly hearts, kiss, etc.), hashtags and so forth can be used has opened up a new channel through which to communicate both the existence and intensity of one's brand 'loving'.

Fans' comments on Instagram posts by sport teams were also aspirational ('aspiring') in nature. As Blackston (2000), and Fionda and Moore (2009) have observed, consumer aspirations are an important component of the branding process, often bound up in issues of self-image and status. Such views resonate with the sport marketing literature, notably the underpinning motives of fandom; in particular, it is reminiscent of the work on BIRGing (Basking in Reflected Glory) (e.g. Wann, Hamlet, \& Hodges, 1995). In the present study, while the comments of the Instagram posts we examined may be underpinned by such a phenomenon, 'aspiring' was specifically characterised by fans commenting to the team's posts ahead of a game (rather than being a response to the result of a game once it has taken place). As such, rather than BIRGing, we propose that 'aspiring'-based comments are more closely linked to expectancy (Lim \& Dubinsky, 2004).

At the same time, social media also makes it easier for fans to comment on teams' posts with a more critical tone ('criticising'), predominantly against all three product-related attributes. The reasons for this may include the difficulty of controlling or moderating criticism in such public forums, the absence of other ways for fans to express their opinions, and the tribal nature of social media environments that may induce people to be rather more open than they would otherwise be. A potential positive fact about these types of comments is the ephemeral social media applications that allow user content to be shared for a set time limit before auto-deletion; in Instagram's case, such a limit can be set at 24 hours. Indeed, recent research has empirically shown that social media followers with greater team identification intend to limit message availability by the self-deletion option, especially when they express a negative experience (Wakefield \& Bennett, 2017). 


\section{Managerial implications}

This research has found that branding remains an important component of a professional sport team's marketing and commercial activities. The roles that star players and club history, for example, play in such branding activities are already well established in the literature. Therefore, we support the contention that images, symbols, slogans and other assets should remain a key part of sport team branding and marketing.

There is no doubt that the proliferation of digital technologies, allied to the growing and now ubiquitous use of social media, is challenging the parameters of existing branding activities among sport teams. Notwithstanding the obvious effects of such developments, such as accessibility and speed of communication, our research indicates that sport team brand managers have to contend with the emergence of new challenges. This includes the nature of content posted on social media platforms, the target audiences for such communications, the control shift from the organisation to the consumer fan (in terms of content and message longevity alike), and the effects the communications are intended to have. At a general level, therefore, an understanding of the semiotics and semantics would seem to be appropriate for sport team brand managers. For example, with a platform such as Instagram where use of text is constrained, crafting meaningful social media posts challenges marketers to think in a creative, thoughtful way. This implies that the next generation of brand managers will need to have a new skill set and, indeed, be entirely familiar with the dynamics of social media use.

Our analysis of Instagram use confirms that social media is a popular, powerful form of engaging with fans, and also an important means through which sport teams can build or accentuate their brands (and the accompanying features and values). The use of images, accompanied by the opportunity for fans to comment and instigate dialogue with one another, 
is both a way to bring brands to life and a new frontier in the process of building customer engagement and enlivening brands.

Therefore, the careful selection of visual content would seem to be important for sport teams' branding decisions. Visual communication can have a powerful impact, which could be positive ( 'loving') or negative ( 'criticising'). It is imperative to ensure that image content communicates the correct message to the relevant audience. This implies that sports marketers will need to develop a new visual literacy if they are to maximise the benefits their teams can derive from using Instagram.

We conclude that while there appears to be consensus that social media can be fraught with pitfalls (most notably that sport teams only have limited control over the content that users post), sport team marketers can affect positive cognition and behaviour among their Instagram followers by carefully selecting images and prompting conversation. This will require a more thoughtful approach to the selection of images and words, and challenge marketers to generate content that is perceived as being genuine rather than contrived.

Nevertheless, we contend that the findings of this study can help team sport marketers bring about the more effective use of social media. For example, referencing the role Instagram plays in enabling remote fans to engage with a team, it is important that marketers understand the basis upon which such engagement takes place and how this might shape the nature of social media communication. The most obvious aspect of this is the use of language, although addressing the way remote fandom interacts with fans' need for a sense of 'belonging' suggests some interesting possibilities for teams. This could include posting content that actively and openly fosters communal and pro-social behaviour among fans, while also providing opportunities to express their love for a team or to constructively contribute to dialogue around, say, a game or a player. 
We also conclude that the use of social media by sport team brands (specifically in respect of the messages they post) has so far been intuitive rather than analytical. Whilst we believe that teams have developed an understanding of the role and purpose of different social media platforms, we argue that professional teams (especially in Europe) need to address the process of message formulation in a more strategic and considered way. This not only implies a need for an understanding of semantics and semiotics, but perhaps also suggests a need for culture change within sport teams. In other words, turning outwards, and becoming more market-focused and communications-driven would seem to be appropriate in building a brand through use of social media. Specifically, spreading information about their brands and producing content that increases fan engagement (particularly in the form of comments) provides sport teams a real opportunity to learn from and about their audience (Brodie, Ilic, Juric, \& Hollebeek, 2013; Yan, 2011). Therefore, sport teams need to carefully monitor and become more involved in online conversations with their customers. The voices of the club, managers or players were noticeably absent from the comments analysed in this study. Furthermore, sport team marketers need to analyse the reasons why a post received increased engagement or even created negative comments from the fans in order to show an "active listening" approach, as well as to avoid repeating similar mistakes in the future (Parganas \& Anagnostopoulos, 2015).

In addition, given that fans are a major stream of revenues for sport teams (Bauer et al., 2008; Richelieu et al., 2011), providing content that increases fan engagement and involvement with the product (the team) can have an impact on the financial success of the team, in several ways. First, the interaction between members in an online community (in this case, the Instagram community of team followers) can affect not only the loyalty towards the community itself but also towards the brand behind it (Popp \& Woratschek, 2016). Second, promoting the games (Biscaia, Correia, Ross, Rosado, \& Maroco, 2013) or emphasising the 
aesthetic characteristics of the stadium (Kerr \& Gladden, 2008) can influence fan behaviour by evoking past memories of the consumption experience. For instance, posting about an upcoming opponent (Event's Image) provides fans with an opportunity to illustrate their support of the home team and work as reminders of past success. Similarly, posts picturing a star player celebrating a goal, particularly when such a goal was scored against rivals or during a significant match, generated the strongest reactions and the largest amounts of comments and likes by the fans, giving them the opportunity to mock opposing teams and players. Such actions, which form part of the daily practices of fans in an online and offline context (Stavros et al., 2014), are reported to have important implications to the fans' identification with their team (Sanderson \& Truax, 2014). Third, content featuring fans and their activities, such as showing them posing in the clubs' shirts, dressing their pets in a similar manner, or showing off birthday cakes with team logos and colours, or any content that provides information about and deeper knowledge of the club, can be viewed as part of relationship-marketing activities by the teams (Abeza, O’Reilly, \& Reid, 2013; Hambrick \& Kang, 2015). Such diverse information can not only enhance a fan's connections to the team, but also strengthen associations of less invested fans as they learn more about the team (Hambrick \& Kang, 2015; Pronschinske et al., 2012; Wallace et al., 2011; Zimmerman et al., 2011). Increasing fan involvement and engagement have been considered as critical factors in explaining consumption behaviours towards team- (Parganas et al., 2015) and sponsor-related products (Ko, Kim, Claussen, \& Kim, 2008).

Besides posts that increase fan engagement, teams can leverage revenues by purely commercial posts, despite the low appeal that such posts may have to fans. For instance, the sponsors, particularly the main shirt sponsors of both teams, become visible not only when a particular picture about them is posted, but also whenever pictures of players, for example celebrating a goal, are uploaded to the teams' Instagram account. Similarly, Brand Mark 
(which includes the logo, shirts, and colours of the club), despite being the subject of a small proportion of photos, was visible next to every description of the uploaded photos. Therefore, we suggest that such disguised advertising offers new opportunities for teams and sponsors to engage in business transactions and could be reflected during the contractual agreements between the parties. However, given the feature of Instagram of a supportive description to each picture, both teams seem to have missed the opportunity to provide a more marketoriented message to their online audience. In almost all cases, the supportive text accurately described the picture, leaving little room for messages beyond the actual instances the picture portrayed. For instance, a picture showing a successful star player could be accompanied by text that could be used as inspiration of how hard work is rewarded, similar to the advertising campaigns of popular sporting apparel brands. Having the star player himself comment on the photograph would also add weight to this message.

Finally, posting about the upcoming match in a particular competition (Event's Image) provides teams with an excellent opportunity to use the brand image of the competition in which they are participating (such as the EPL) as a co-driver in their branding activities (Kunkel et al., 2012). Such cross-promotion and co-branding activities with entities of large amounts of online following can also include (former) star players or coaches, as our findings suggest. Thus, we recommend that sport teams set up policies and establish synergies with their players' profiles, particularly those with a large online following base. Even more, such synergies may be formalised during the contract negotiations in order to include co-branding activities as part of their contractual duties.

\section{Limitations and further research}

This study was exploratory in nature, as research on social media (and particularly Instagram) branding in sports needs further development as the platforms and strategies mature. While the results could apply to similar teams (football clubs with comparable success, brand value 
and social media appeal), they cannot be easily generalised to wider populations. Therefore, ongoing research on this area is warranted and this study sets the foundation for such future work. For instance, it would be worthwhile including additional teams from the same league, other leagues, or even other sports, particularly with different characteristics (that is, lower brand value and/or social media appeal). Furthermore, it would be interesting to see whether different patterns of branding exist in different periods (off-season vs. on-season) or different social media outlets. In addition, understanding the links between social media and consumers (fans) will become increasingly relevant for the financial welfare of sport organisations. To this end, additional qualitative research of interviews with fans who made the comments could provide significant implications for sport teams about how to use Instagram (and other social media, for that matter) more effectively. Similarly, while this study analysed star player posts and their effects on fan engagement, it would be interesting to provide more in-depth analysis of the effect the presence of key team figures (such as current and former star players and coaches) has on fan engagement. A further limitation can be observed from a methodological perspective: inter-coder reliability in this study was measured using two methods for all posts: (a) the percentage of agreement between the coders, and (b) Cohen's kappa. However, inter-coder reliability could be increased by performing tests on all variables used in this study in addition to all posts. From a more technical perspective, the change in Instagram's API is something to be noted. According to the new algorithm, the order of photos and videos in one's feed will be based on the interest in the content, the relationship with the content provider, and the timeliness of the post (Instagram, 2016). Severe changes on fans' engagement, however, should not be expected given the daily interest of fans and their interaction with the content provided by the team (Broughton, 2012; Parganas and Anagnostopoulos, 2015). Finally, from a purely business 
perspective, it would be useful to investigate the actual return on investment (ROI) of social media to sport teams.

\section{Conclusion}

The present study starts to fill a gap in the literature about how sport organisations make use of social networks as branding tools. Overall, this study has highlighted the evolving use of Instagram by sport teams to provide brand-related information and interaction with fans. Results revealed that the existing team brand literature can be applied in the social media context. In particular, all brand attributes of the adopted model were part of Instagram posts, albeit to a different extent. Teams using Instagram are able to produce and control their own news and stories and should recognise the importance of giving fans insights about their organisations, whether in the form of player/team news developments or information and activities beyond the playing field. Instagram (and all other social media channels) is capable of giving fans a more active role, either through the Comment feature or by sharing photos provided by fans through the official teams' channels. Fans recognise value in these transactions, and they subsequently engage by expressing their love ('loving'), hopes and expectations ('aspiring'), need for belongingness to the team ('belonging'), but also their concerns ('criticising') about organisational behaviour (on and off the field). Therefore, we envisage that the insights of the present study will provide a much-needed access point into the discussions on brand management enhancement through social media in the context of professional team sports. 


\section{References}

Aaker, D.A. (1991). Managing brand equity. New York: The Free Press.

Abeza, G., O’Reilly, N. \& Reid, I. (2013). Relationship marketing and social media in sport. International Journal of Sport Communication, 6(2), 120-142.

Abeza, G., O’Reilly, N., Seguin, B. \& Nzindukiyimana, O. (2015). Social media scholarship in sport management research: A critical review. Journal of Sport Management, 29(6), 601-618.

Albert, N. \& Merunka, D. (2013). The role of brand love in consumer-brand relationships. Journal of Consumer Marketing, 30(3), pp.258-266.

Arai, A., Ko, Y.J. \& Ross, S. (2014). Branding athletes: Exploration and conceptualization of athlete brand image. Sport Management Review, 17(2), 97-106.

Anagnostopoulos, C. \& Shilbury, D. (2013). Implementing corporate social responsibility in English football: Towards multi-theoretical integration. Sport, Business, and Management: An International Journal, 3(4), 268-284.

Anagnostopoulos, C., Byers, T. \& Shilbury, D. (2014). Corporate social responsibility in team sport organisations: toward a theory of decision-making. European Sport Management Quarterly, 14(3), 259-281.

Anagnostopoulos, C., Gillooly, L., Cook, D., Parganas, P. Chadwick, S. (2016). Stakeholder communication in 140 characters or less: A study of community sport foundations. Voluntas: International Journal of Voluntary and Nonprofit Organisations. In Print.

Baig, E. (2013). Instagram rolls out direct messaging. http://www.usatoday.com/story/tech/columnist/baig/2013/12/12/instagramdirect/3998413/, accessed 22 December 2015. 
Ballouli, K. (2010). Digital-branding and social media strategies for professional athletes, sports teams, and leagues: An interview with Digital Royalty's Amy Martin. International Journal of Sport Communication, 3(4), 395-401.

Bauer, H.H., Stockburger-Sauer, N.E. \& Exler, S. (2008). Brand image and fan loyalty in professional team sport: A refined model and empirical assessment. Journal of Sport Management, 22(2), 205-226.

Batra, R., Ahuvia, A., \& Bagozzi, R.P. (2012). Brand love. Journal of Marketing, 76(2), pp.1-16.

Beech, J. \& Chadwick, S. (2007). The marketing of sport. Edinburgh, UK: Pearson Education.

Biscaia, R., Correia, A., Ross, S., Rosado, A. \& Maroco, J. (2013). Spectator-based brand equity in professional soccer. Sport Marketing Quarterly, 22(1), 20-32.

Blackston, M. (2000). Observations: Building brand equity by managing the brand's relationships. Journal of Advertising Research, 40(6), pp.101-105.

Blumrodt, J., Bryson, D. \& Flanagan, J. (2012). European football teams' CSR engagement impacts on customer-based brand equity. Journal of Consumer Marketing, 29(7), 482-493.

Boyd, D.M. \& Ellison, M.B. (2008). Social network sites: Definition, history, and scholarship. Journal of Computer-Mediated Communication, 13(1), 210-230.

Boyle, B.A. \& Magnusson, P. (2007). Social identity and brand equity formation: A comparative study of collegiate sports fans. Journal of Sport Management, 2(4), 497-520.

Brand Finance (2015). Brand Finance football 502015 - The annual report on the world's most valuable football brands. Retrieved from: 
http://brandfinance.com/images/upload/bf_football_50_for_website.pdf , accessed 29 March 2016.

Greenwood, P., Kanters, M.A. \& Casper, J.M. (2006). Sport fan team identification formation in mid-level professional sport. European Sport Management Quarterly, 6(3), pp.253265.

Brodie, R.J., Hollebeek, L., Juric, B. \& Ilic, A. (2011). Customer Engagement: Conceptual Domain, Fundamental Propositions \& Implications for Research in Service Marketing. Journal of Service Research, 14(3), 252-271.

Brodie, R.J., Ilic, A., Juric, B. \& Hollebeek, L. (2013). Consumer engagement in a virtual brand community: an exploratory analysis, Journal of Business Research, 66(8), 105-114.

Broughton, D. (2012). Survey: Social media continues to fuel fans. Street and Smith's Sports Business Journal, 16(22), 24.

Browning, B. \& Sanderson, J. (2012). The positives and negatives of Twitter: Exploring how student-athletes use Twitter and respond to critical tweets. International Journal of Sport Communication, 5(4), 503-521.

Bruhn, M., Schoenmueller, V. \& Schaefer, D.B. (2012). Are social media replacing traditional media in terms of brand equity creation? Management Research Review, 35(9), 770-790.

Cho, M., Schweickart, T. \& Haase, A. (2014). Public engagement with nonprofit organisations on Facebook. Public Relations Review, 40(3), 565-567.

Clavio, G. (2013). Emerging social media and applications in sport. In P. Pedersen, (Ed.). Handbook of sport communication (pp.259-268). New York, NY: Routledge.

Clavio, G. \& Walsh, P. (2013). Dimensions of social media utilization among college sport fans. Communication \& Sport, 2(3), 261-281. 
Constine, J. (2017). Instagram's growth speads up as it hits 700 million users. Retrieved from https://techcrunch.com/2017/04/26/instagram-700-million-users/ - 26 April, 2017.

Cooper, C. (2010). New media marketing: The innovative use of technology in NCAA athletic department e-branding initiatives. Journal of Marketing Development and Competitiveness, 5(1), 23-32.

Crabtree, B.F. \& Miller. L.W. (1992) A template approach to text analysis: Developing and using codebooks. Doing Qualitative Research. In B. F. Crabtree and W. L. Miller. Newbury Park, CA, Sage Publications (pp. 93-109).

Deloitte (2015). Deloitte annual review of football finance. http://www2.deloitte.com/content/dam/Deloitte/global/Documents/Audit/gxfootball-money-league-2015.pdf, accessed 15 November 2015.

Eagleman, A.N. (2013). Acceptance, motivations, and usage of social media as a marketing communications tool amongst employees of sport national governing bodies. Sport Management Review, 16(4), 488-497.

Eagleman, A.N. \& Krohn, B.D. (2012). Sponsorship awareness, attitudes, and purchase intentions of road race series participants. Sport Marketing Quarterly, 21(4), 210220.

Embury-Dennis, T. (2015). Jurgen Klopp mentioned two million times on Twitter since the week leading up to his appointment as Liverpool manager. http://www.dailymail.co.uk/sport/football/article-3269573/Jurgen-Klopp-mentioned-

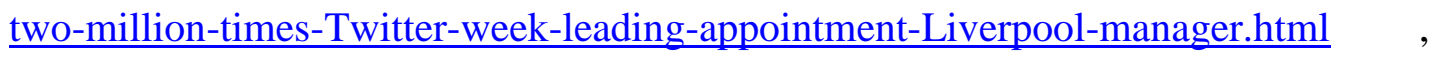
accessed 15 October 2015.

English Premier League [EPL] (2015) About the Premier League. http://www.premierleague.com/content/premierleague/en-gb/about/a-growing-fanbase/ , accessed 13 March 2016. 
Ferrand, A. \& Pages, M.P. (1999). Image management in sport organisations: The creation of value. European Journal of Marketing, 33(3/4), 387-402.

Filo, K., Lock, D. \& Karg, A. (2015). Sport and social media research: A review. Sport Management Review, 18(2), 166-181.

Fionda, A.M. \& Moore, C.M. (2009). The anatomy of the luxury fashion brand. Journal of Brand Management, 16(5-6), pp.347-363.

Frederick, E., Lim, C.H., Clavio, G., Pedersen, P.M., \& Burch, L.M. (2014). Choosing between the one-way or two-way street: An exploration of relationship promotion by professional athletes on Twitter. Communication \& Sport, 2(1), 80-99. doi:10.1177/2167479512466387

Frey, L., Botan, C. \& Kreps, G. (2000). Investigating communication: An introduction to research methods, $2^{\text {nd }}$ edition, Boston: Allyn and Bacon.

Geurin-Eagleman, A. \& Burch, L. (2016). Communicating via photographs: A gendered analysis of Olympic athletes' visual self-presentation on Instagram. Sport Management Review, 19(2), 133-145.

Gibbons, T. \& Dixon, K. (2010). 'Surf's up!': A call to take English soccer fan interactions on the Internet more seriously. Soccer \& Society, 11(5), 599-613.

Gibbs, C., O’Reilly, N. \& Brunette, M. (2014). Professional team sport and Twitter: Gratifications sought and obtained by followers. International Journal of Sport Communication, 7(2), 188-213.

Gladden, J. \& Funk, D. (2002). Developing an understanding of brand associations in team sports: Empirical evidence from consumers of professional sport. Journal of Sport Management, 16(1), 54-81.

Gladden, J. \& Milne, G. (1999). Examining the importance of brand equity in professional sport. Sport Marketing Quarterly, 8(1), 21-29. 
Graham, A.B. (2013). The 60 best athletes to follow on Instagram. http://extramustard.si.com/2013/01/30/the-60-best-athletes-to-follow-on-instagram/, accessed December 22, 2015.

Gummerus, J., Liljander, V., Weman, E. \& Pihlström, M. (2012). Customer engagement in a Facebook brand community. Management Research Review, 35(9), 857-877.

Hambrick, M.E. \& Kang, S.J. (2015). Pin it: Exploring how professional sports organisations use Pinterest as a communications and relationship-marketing tool. Communication \& Sport, 3(4), 434-457.

Hambrick, M.E., Simmons, J.M., Greenhalgh, G.P. \& Greenwell, T.C. (2010). Understanding professional athletes' use of Twitter: A content analysis of athlete tweets. International Journal of Sport Communication, 3(4), 454-471.

Hanna, R., Rohm, A. \& Crittenden, V. (2011). We're all connected: The power of the social media ecosystem. Business Horizons, 54(3), 265-273.

Hollebeek, L. (2011). Exploring Customer Brand Engagement: Definition and Themes. Journal of Strategic Marketing, 19(7), 555-573.

Hutter, K., Hautz, J., Dennhardt, S. \& Fuller, J. (2013). The impact of user interactions in social media on brand awareness and purchase intention: the case of MINI on Facebook, Journal of Product and Brand Management, 22(5), 342-351.

Instagram (2015). Stats. https://www.instagram.com/press, accessed 20 January, 2016.

$\begin{array}{lllll}\text { Instagram } & \text { (2016). } & \text { Update } & \text { on } & \text { Feed }\end{array}$ https://help.instagram.com/1617763228546325?helpref=uf_permalink, accessed 20 June, 2017.

Kaplan, A.M. \& Haenlein, M. (2010). Users of the world, unite! The challenges and opportunities of Social Media. Business Horizons, 53(1), 59-68. 
Kassing, J.W. \& Sanderson, J. (2010). Fan-athlete interaction and Twitter. Tweeting through the Giro: A case study. International Journal of Sport Communication, 3(1), 113128.

Kaynak, E., Salman, G. and Tatoglu, E. (2008). An integrative framework linking brand associations and brand loyalty in professional sports. Journal of Brand Management, 15(5), 336-357.

Keller, K. L. (1993). Conceptualizing, measuring, and managing customer-based brand equity. Journal of Marketing, 57(1), 1-22.

Keller, K.L. (2009). Building strong brands in a modern marketing communications environment. Journal of Marketing Communications, 15(2-3), 139-155.

Kerr, A.K. \& Gladden, J.M. (2008). Extending the understanding of professional team brand equity to the global marketplace. International Journal of Sport Management and Marketing, 3(1/2), 58-77.

Kietzmann, J.H., Hermkens, K., McCarthy, I.P. \& Silvestre, B.S. (2011). Social media? Get serious! Understanding the functional building blocks of social media, Business Horizons, 54(3), 241-251.

Kim, A. J. \& Hull, K. (2017). How fans are engaging with baseball teams demonstrating multiple objectives on Instagram", Sport, Business and Management: An International Journal, 7(2), 216-232.

Kim, A. J. \& Ko, E. (2012). Do social media marketing activities enhance customer equity? An empirical study of luxury fashion brand. Journal of Business Research, 65(10), $1480-1486$.

Ko, Y.J., Kim, K., Claussen, C. \& Kim, T.H. (2008). The effects of sport involvement, sponsor awareness and corporate image on intention to purchase sponsors' products. International Journal of Sports Marketing \& Sponsorship, 9(2), 79-94. 
Koetsier, J. (2013, December 5). Instagram is the 'best platform for brands' in 2013 beating out Facebook, Twitter, and Google+. http://venturebeat.com/2013/12/05/instagramthe-best-platform-for-brands-in-2013-beating-out-facebook-twitter-and-google/ , accessed December 22, 2015.

Kunkel, T., Funk, D.C., and King, C. (2012). Developing a conceptual understanding of consumer-based league brand associations. Journal of Sport Management, 28(1), 4967.

Lebel, K. \& Danylchuk, K. (2014). Facing off on Twitter: A generation Y interpretation of professional athlete profile pictures. International Journal of Sport Communication, 7(3), 317-336.

Lim, H. \& Dubinsky, J. A. (2004). Consumers' perceptions of e-shopping characteristics: an expectancy-value approach. Journal of Services Marketing, 18(7), 500-513.

Lipsman, A., Mudd, G., Rich, M. \& Bruich, S. (2012). The power of "Like" - How brands reach (and influence) fans through social-media marketing. Journal of Advertising Research, 52(1), 40-52.

Liverpool FC (2015). News. http://www.liverpoolfc.com/news/latest-news/180970-lfcannounces-financial-results, accessed 4 March 2015.

McCarthy J., Rowley J., Ashworth C.J. \& Pioch E. (2014). Managing brand presence through social media: the case of UK football clubs. Internet Research, 24(2), 181-204.

McLaren, D. (2013). How Everton FC perform on Facebook. http://www. theuksportsnetwork.com/how-everton-fc-perform-on-facebook-infograph, accessed November 1, 2014.

Miles, M. B., Huberman, A. M., \& Saldana, J. (2013). Qualitative data analysis: A methods sourcebook ( $3^{\text {rd }}$ ed.). Thousand Oaks, CA: Sage Publications. 
Miners, Z. (2013, August 7). Instagram gets new features including video import. http://www.computerworld.com/s/article/9241449/Instagram_gets_more_features_in cluding_video_import, accessed December 222015.

O'Shea, M., and Alonso, A.D. (2011). Opportunity or obstacle? A preliminary study of professional sport organisations in the age of social media. International Journal of Sport Management and Marketing, 10(3/4), 196-212.

Ozsoy, S. (2011). Use of new media by Turkish fans in sport communication: Facebook and Twitter. Journal of Human Kinetics, 28(2), 165-176.

Paine, D. K. (2011). Measure what matters: Online tools for understanding customers, social media, engagement, and key relationships. Hoboken, New Jersey: John Wiley \& Sons.

Parganas, P. \& Anagnostopoulos, C. (2015). Social media strategy in professional football: The case of Liverpool FC. Sports Management International Journal Choregia, 11(2), 62-75. DOI: http:dx.doi.org/10.4127/ch.2015.0102

Parganas, P., Anangnostopoulos, C. \& Chadwick, S. (2015). "You'll never tweet alone": Managing sport brands through social media. Journal of Brand Management, 22(7), $551-568$.

Pedersen, P. M. (2014). A commentary on social media research from the perspective of a sport communication journal editor. Communication and Sport, 2(2), 138-142.

Pegoraro, A. (2010). Look who's talking - Athletes on Twitter: A case study. International Journal of Sport Communication, 3(4), 501-514.

Pegoraro, A. \& Jinnah, N. (2012). Tweet 'em and reap 'em: The impact of professional athletes' use of Twitter on current and potential sponsorship opportunities. Journal of Brand Strategy, 1(1), 85-97. 
Pronschinske, M., Groza, M. \& Walker, M. (2012). Attracting Facebook 'fans': The importance of authenticity and engagement as a social networking strategy for professional sport teams. Sport Marketing Quarterly, 21(4), 221-231.

Popp, B. \& Woratschek, H. (2016). Introducing branded communities in sport for building strong brand relations in social media. Sport Management Review, 19(2), 183-197.

Price, J., Farrington L. \& Hall L. (2013). Changing the game? The impact of Twitter on relationships between football clubs, supporters and the sports media, Soccer \& Society, 14(4), 446-461.

Ratchford, T. B. (2015). Some directions for research in interactive marketing. Journal of Interactive Marketing, 29, v-vii.

Rein, I., Shields, B. \& Grossman, A. (2015). The Sports Strategist: Developing leaders for a high-performance industry. Oxford University Press.

Riffe, D., Lacy, S. \& Fico, F.G. (2005). Analyzing media messages: Using quantitative content analysis in research (2nd ed.). New York: Lawrence Erlbaum Associates, Inc. Mahwah.

Robinson, M.J. \& Trail, G.T. (2005). Relationships among spectator gender, motives, points of attachment, and sport preference. Journal of Sport management, 19(1), pp.58-80.

Ross, S. (2006). A conceptual framework for understanding spectator-based brand equity. Journal of Sport Management, 20(1), 22-38.

Ross, S., James, J. \& Vargas, P. (2006). Development of a scale to measure team brand associations in professional sport. Journal of Sport Management, 20(2), 260-279.

Ross, S. D., Russell, K. C. \& Bang, H. (2008). An empirical assessment of spectator-based brand equity. Journal of Sport Management, 22(3), 322-337.

Rowe, D. (2014). Following the followers sport researchers' labour lost in the twittersphere? Communication \& Sport, 2(2), 117-121. 
Sanderson, J. \& Truax, C. (2014). “I hate you man!"’: Exploring maladaptive parasocial interaction expressions to college athletes via Twitter. Journal of Issues in Intercollegiate Athletics, 7: 333-351.

Schivinski, B. \& Dabrowski, D. (2015). The impact of brand communication on brand equity through Facebook. Journal of Research in Interactive Marketing, 9(1), 31-53.

Shen, B. \& Bissell, K. (2013). Social media, social me: A content analysis of beauty companies' use of Facebook in marketing and branding. Journal of Promotion Management, 19(5), 629-651.

Shively, K. (2014, October 28). Simply measured Q3 2014 Instagram study. http://simplymeasured.com/library/2014-q3-instagram-study/?aliId=37674326, accessed December 22, 2015.

Simply Measured (2013). Study: How top brand marketers use Instagram. http://cdn.simplymeasured.com/wpcontent/uploads/2013/10/Simply_Measured_Instagram_Study.pdf, $\quad$ accessed December 222015.

Smith, T. (2009). The social media revolution. International Journal of Market Research, 51(4), 559-561.

Smith R.L. \& Sanderson, J. (2015). I'm going to Instagram it! An analysis of athlete selfpresentation on Instagram. Journal of Broadcasting \& Electronic Media, 59(2), $342-358$.

Socialbakers (2015). Brands. http://www.socialbakers.com/, accessed 20 December, 2015.

Sport+Markt (2010). The most popular football clubs. http://www.goal.com/en/news/12/spain/2010/09/10/2112594/barcelona-and-realmadrid-have-the-most-fans-in-europe, accessed 20 December, 2015. 
Statista (2017). Number of social media users worldwide from 2010 to 2020 (in billions) https://www.statista.com/statistics/278414/number-of-worldwide-social-networkusers/accessed 7 June 2017.

Stavros, C., Meng, M., Westberg, K. \& Farrelly, F. (2014). Understanding fan motivation for interacting on social media. Sport Management Review, 17(4), 455-469.

Strauss, A. \& Corbin, J. (1998). Basics of qualitative research: Procedures and techniques for developing grounded theory. Newbury Park, CA: Sage.

Truong, A. (2014, February 13). This report shows why brands should embrace Instagram (if they haven't already). http://www.fastcompany.com/3026419/fast-feed/this-reportshows-why-brands-should-embrace-instagram-if-the-havent-already, $\quad$ accessed December 222015.

Wallace, L., Wilson, J. \& Miloch, K. (2011). Sporting Facebook: A content analysis of NCAA organisational sport pages and Big 12 conference athletic department pages. International Journal of Sport Communication, 4(4), 422-444.

Wakefield, T.L. \& Bennett, G. (2017). Sports fan experience: Electronic word-of-mouth in ephemeral social media. Sport Management Review, Online first: DOI: http://dx.doi.org/10.1016/j.smr.2017.06.003.

Wann, D.L., Hamlet, M.A., Wilson, T.M. \& Hodges, J.A. (1995). Basking in reflected glory, cutting off reflected failure, and cutting off future failure: The importance of group identification. Social Behavior and Personality: An International Journal, 23(4), $377-388$.

Whiteside, E., Yu, N. \& Hardin, M. (2012). The new "toy department"?: A case study on differences in sports coverage between traditional and new media. Journal of Sports Media, 7(1), 23-38. 
Williams, J. \& Chinn, S.J. (2010). Meeting relationship-marketing goals through social media: a conceptual model for sport marketers. International Journal of Sport Communication, 3(4), 422-437.

Yan, J. (2011). Social media in branding: Fulfilling a need. Journal of Brand Management, $18(9), 688-696$.

Zimmerman, M., Clavio, G. \& Lim, C.H. (2011). Set the agenda like Beckham: A professional league's use of YouTube to disseminate messages to its users. International Journal of Sport Management and Marketing, 10(3/4), 180-195.

Table 1: Description of brand attributes used in this study

\begin{tabular}{|c|c|c|c|}
\hline & Brand attribute & Description & Example Instagram post \\
\hline 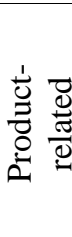 & $\begin{array}{l}\text { Star Player(s) } \\
\text { Head Coach }\end{array}$ & $\begin{array}{l}\text { Success of the team, quality/style of } \\
\text { play of the team } \\
\text { High quality and/or highly } \\
\text { recognizable players } \\
\text { Successful, charismatic or iconic } \\
\text { head coach }\end{array}$ & $\begin{array}{l}\text { The team in action or celebrating a } \\
\text { goal } \\
\text { The player in action during the match } \\
\text { or in training } \\
\text { Coach giving orders during the } \\
\text { match or at the training }\end{array}$ \\
\hline \multirow{8}{*}{ 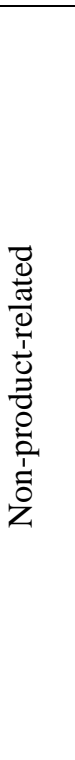 } & Brand Mark & The logo, mascot, colors and & The logo or the shirt of the club \\
\hline & Management & $\begin{array}{l}\text { The executive management of the } \\
\text { club }\end{array}$ & $\begin{array}{l}\text { Pictures or announcements of } \\
\text { executive management }\end{array}$ \\
\hline & $\begin{array}{l}\text { Club's History and } \\
\text { Tradition }\end{array}$ & $\begin{array}{l}\text { Winning records, past success, } \\
\text { tragedies, legendary matches, past } \\
\text { players and coaches }\end{array}$ & $\begin{array}{l}\text { Pictures of past players, coaches or } \\
\text { matches }\end{array}$ \\
\hline & $\begin{array}{l}\text { Club's Culture and } \\
\text { Values }\end{array}$ & $\begin{array}{l}\text { Values/culture of the team, its role in } \\
\text { the community }\end{array}$ & $\begin{array}{l}\text { The players visiting a hospital or a } \\
\text { charitable event }\end{array}$ \\
\hline & Event's Image & $\begin{array}{l}\text { The image of a particular competition } \\
\text { or the opponent (rivalry) }\end{array}$ & Announcement of the next match \\
\hline & Sponsor & $\begin{array}{l}\text { The image of the main sponsor, its } \\
\text { association with the club }\end{array}$ & $\begin{array}{l}\text { Usually information about a contest } \\
\text { organized by the teams' main } \\
\text { sponsor }\end{array}$ \\
\hline & Fans & $\begin{array}{l}\text { Not just customers, essential part of a } \\
\text { unique product }\end{array}$ & $\begin{array}{l}\text { Pictures of fans in various occasions } \\
\text { such as celebrating, in front of the } \\
\text { stadium etc. }\end{array}$ \\
\hline & Stadium & $\begin{array}{l}\text { The arena, facilities, concessions at } \\
\text { the stadium }\end{array}$ & Views of the stadium \\
\hline
\end{tabular}




\begin{tabular}{l|ccc|ccc|ccc}
\hline \multicolumn{1}{c}{ Table 2: Overview of posts and fan responses } & \multicolumn{1}{c}{ comments, likes) } \\
\hline & \multicolumn{3}{c|}{ Instagram posts } & \multicolumn{3}{c|}{ Comments } & \multicolumn{4}{c}{ Like } \\
& TOTAL & M & SD & TOTAL & M & SD & TOTAL & M & SD \\
LFC & 1059 & 3.54 & 0.94 & 954,140 & 896.62 & 1129.01 & $78,440,691$ & $74,585.17$ & $20,344.60$ \\
MU & 1048 & 3.50 & 0.99 & $2,009,778$ & 1847.90 & 2617.60 & $177,235,651$ & $169,590.32$ & $143,420.95$ \\
\hline
\end{tabular}

\begin{tabular}{lccccc}
\hline \multicolumn{5}{l}{ Table 3: Differences in brand attributes posted in } & \multicolumn{5}{c}{ Instagram by the two teams } \\
\hline Brand Attribute & \multicolumn{2}{c}{ LFC $(\mathbf{N = 1 0 5 9})$} & \multicolumn{2}{c}{ MU $(\mathbf{N = 1 0 4 8})$} & Chi-square significance \\
& Frequency & $\%$ & Frequency & $\%$ & \\
\hline Team Success & 251 & $23.69 \%$ & 225 & $21.42 \%$ & No significance \\
Star Player & 368 & $34.77 \%$ & 347 & $33.09 \%$ & No significance \\
Head Coach & 132 & $12.46 \%$ & 16 & $1.57 \%$ & $\chi^{2}=90.919, p<.001$ \\
Brand Mark & 50 & $4.74 \%$ & 22 & $2.07 \%$ & No significance \\
Management & 1 & $0.09 \%$ & 18 & $1.69 \%$ & $\chi^{2}=15.211, p<.001$ \\
Club's History \& Tradition & 54 & $5.13 \%$ & 110 & $10.52 \%$ & $\chi^{2}=19.122, p<.001$ \\
Club's Culture and Values & 14 & $1.29 \%$ & 30 & $2.86 \%$ & $\chi^{2}=5.818, p=.016$ \\
Event's Image & 91 & $8.63 \%$ & 93 & $8.85 \%$ & No significance \\
Sponsor & 21 & $1.94 \%$ & 22 & $2.07 \%$ & No significance \\
Fans & 25 & $2.37 \%$ & 75 & $7.17 \%$ & $\chi^{2}=25.000, p<.001$ \\
Stadium & 46 & $4.31 \%$ & 76 & $7.27 \%$ & $\chi^{2}=7.377, p=.007$ \\
Other & 6 & $0.57 \%$ & 15 & $1.43 \%$ & $\chi^{2}=3.857, p=.05$ \\
\hline
\end{tabular}

\begin{tabular}{lcccc}
\hline \multicolumn{5}{c}{ Table 4: Comparison of fan responses (comments and like) per brand attribute } \\
\hline \multirow{2}{*}{ Brand attribute } & LFC & \multicolumn{3}{c}{ MU } \\
& Comment $(\boldsymbol{M})^{*}$ & Like $(\boldsymbol{M})^{*}$ & Comment $(\boldsymbol{M})^{*}$ & Like $(\boldsymbol{M})^{*}$ \\
\hline Team Success & $1,000.13$ & $79,617.12$ & $10,370.78$ & $137,672.35$ \\
Star Player & 959.23 & $84,881.56$ & $1,440.56$ & $215,385.43$ \\
Head Coach & $3,117.78$ & $127,773.45$ & $1,181.67$ & $122,468.32$ \\
Brand Mark & 288.12 & $65,988.32$ & $1,544.76$ & $154,288.11$ \\
Management & 302.34 & $43,851.34$ & 518.45 & $73,938.21$ \\
Club's History \& Tradition & 311.23 & $62,489.56$ & $1,707.24$ & $238,893.77$ \\
Club's Culture and Values & 227.94 & $57,945.59$ & 903.44 & $188,662.82$ \\
Event's Image & 421.02 & $53,091.98$ & $1,867.15$ & $172,645.22$ \\
Sponsor & 840.43 & $49,068.77$ & 872.23 & $126,118.9$ \\
Fans & 426.84 & $53,863.45$ & 591.32 & $145,765.56$ \\
Stadium & 981.81 & $73,750.32$ & $1,239.29$ & $191,268.39$ \\
\hline
\end{tabular}


Table 5: Differences in fan responses (comments, likes) to product and non-product related posts

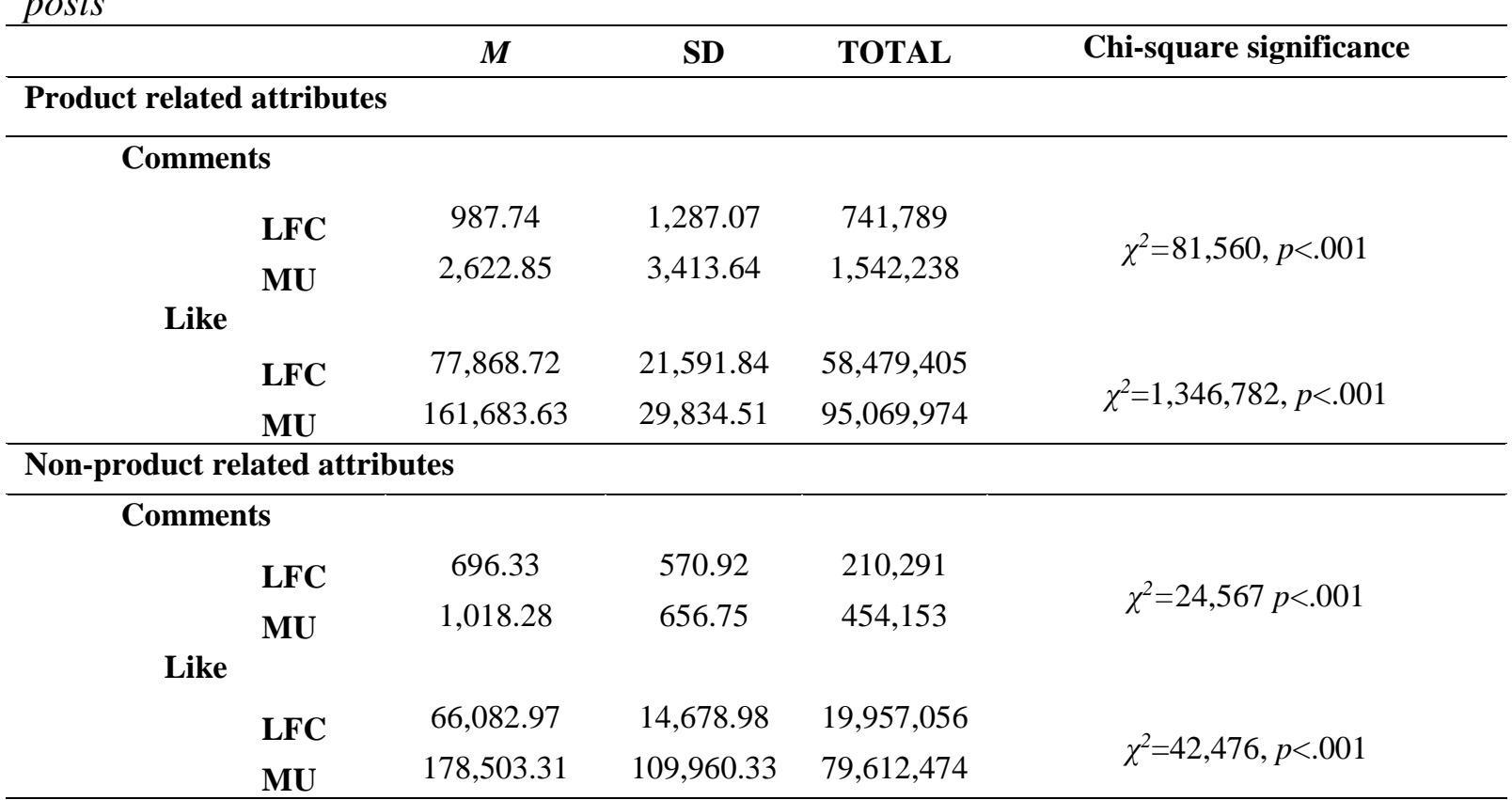

\begin{tabular}{|c|c|c|}
\hline $\begin{array}{l}\text { Higher order } \\
\text { themes }\end{array}$ & Themes description & Illustrative data extracts \\
\hline Aspiring & $\begin{array}{l}\text { Positive comments } \\
\text { which aspire for the } \\
\text { team to succeed }\end{array}$ & $\begin{array}{l}\text {--Come on Liverpool we've got to get the } 25,000 \text { goal this } \\
\text { weekend. } \\
\text {--Just bcoz Chelsea to an easy early run they are still no } \\
\text { match for us... We beat them at their pitch and when they } \\
\text { can to Anfield. } \\
\text {--Liverpool you will be victory tonight ! } \\
\text {--Bad luck we lost this weekend but hold your heads up } \\
\text { high we should give Chelsea a good game tomorrow night } \\
\text { come on you reds } \\
\text {--come on man u can do it } \\
\text {--This is the only trophy we don't have in our cabinet . } \\
\text { Jose this would be a cracker of start to win this }\end{array}$ \\
\hline Belonging & $\begin{array}{l}\text { Positive comments } \\
\text { which demonstrate } \\
\text { unity or a particular } \\
\text { bonding with the } \\
\text { team }\end{array}$ & $\begin{array}{l}\text {--My first PL game attended at Anfield. Will never forget } \\
\text { it \#ynwa } \\
\text {--We got the best fans no doubts } \\
\text {--Its not a stadium it our home } \\
\text {--Once a red always a red! }\end{array}$ \\
\hline Criticising & $\begin{array}{l}\text { Negative comments } \\
\text { which are critical of } \\
\text { the team }\end{array}$ & $\begin{array}{l}\text {--YNMA=You'll Never Win Again } \\
\text {--After losing Liverpool is just a big disgrace to their } \\
\text { entire fan } \\
\text {--Why don't we win bad team } 2 \text {; }\end{array}$ \\
\hline Loving & $\begin{array}{l}\text { Positive Comments } \\
\text { which feature the } \\
\text { word love or a } \\
\text { heart/love emoticon } \\
\text { directed as a positive } \\
\text { thing toward the team }\end{array}$ & $\begin{array}{l}\text {--I love you Liverpool } \\
\text {--REDS LOVE YOU } \\
\text {-- }-\odot \odot \odot \\
\text {--Love you }\end{array}$ \\
\hline
\end{tabular}


